\title{
El arbitraje ¿divinidad jurídica o jurisdicción incompleta?
}

\author{
The Arbitration \\ ¿Legal Divinity or Incomplete Jurisdiction
}

Daniel Alberto Juárez Fernández* https://orcid.org/0000-0002-4140-1543

http://dx.doi.org/10.21503/lex.v19i28.2320

* Abogado al servicio del Estado. Docente Universitario en Universidad Tecnológica del Perú, Universidad Inca Garcilaso de la Vega, Universidad Federico Villarreal, Universidad Privada San Juan Bautista, e Instituto Superior Tecnológico. Estudios concluidos de Maestría en Derecho Empresarial, Maestría en Tutela de Derechos, Maestría en Gestión Pública y Doctorado en Derecho. Perú.

Correo electrónico: djf38495@hotmail.com

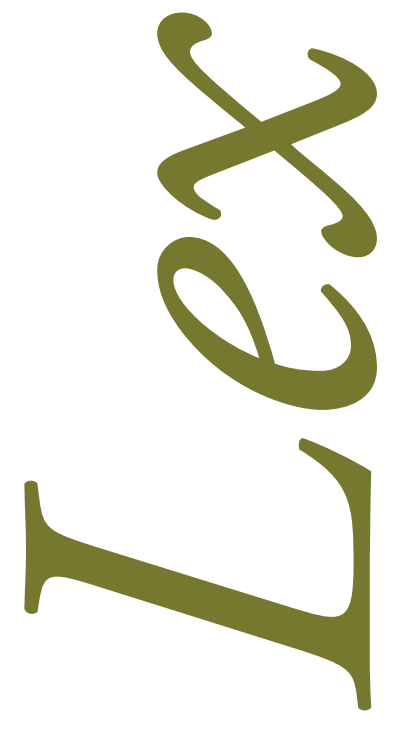




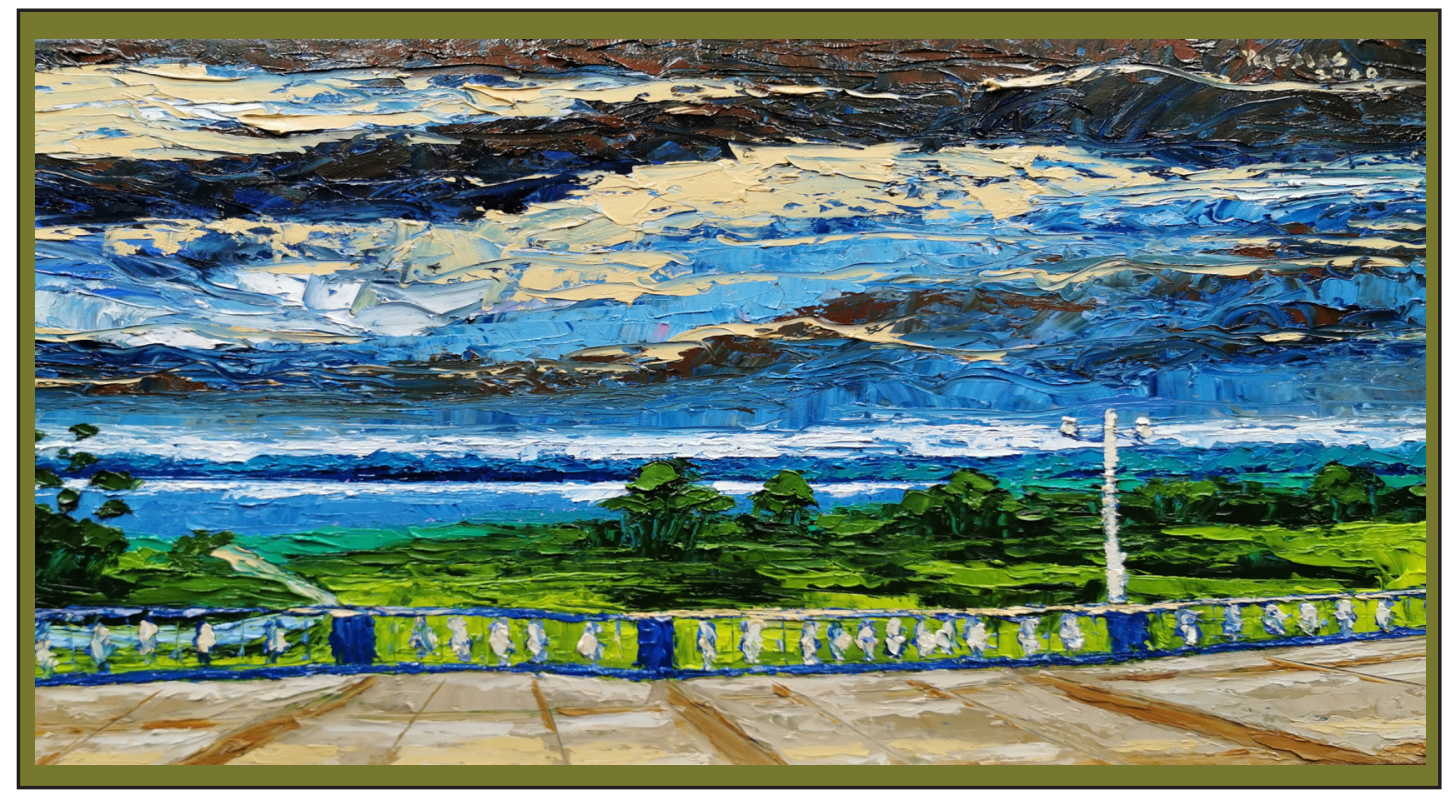

Boulevard de Iquitos. Óleo sobre tela, 31 X $41 \mathrm{~cm}$. Javier Yglesias Sánchez (Iquitos, Perú, 1963) Correo electrónico: javieryglesiassanchez@hotmail.com 


\section{RESUMEN}

Existe un riesgo potencial por el cumplimiento de decisiones emitidas fuera del marco de competencia de las Entidades, las cuales consisten en los mandatos de Tribunales Arbitrales, que vulneran la obligación jurídica de motivación. En nuestro marco jurídico desapareció la posibilidad de una segunda instancia arbitral, por lo que en este momento de la historia, el Estado Peruano, como cualquier litigante, se ve imposibilitado de cuestionar el fondo del laudo, no por una cuestión de acuerdo de voluntades, sino por la verticalidad de la Ley; por lo que surgen diversos aspectos de relevancia jurídica, como son los casos del perdedor injusto o conforme a nuestra materia, el dańo potencial al Estado cuando se ordena el pago a favor de un privado con cargo a fondos públicos basados en una decisión irrevisable e injusta.

Palabras clave: jurisdicción, arbitraje, motivación jurídica.

\section{ABSTRACT}

There is a potential risk for compliance with decisions issued outside the framework of competence of the Entities, which consist of the mandates of Arbitral Courts that violate-the legal obligation of motivation. In our legal framework, the possibility of a second arbitration instance disappeared, so that at this moment in history, the Peruvian State, like any litigant, is unable to question the merits of the award, not because of a matter of agreement of wills, but because of the verticality of the Law; Therefore, various aspects of legal relevance arise, such as the cases of the unjust loser or in accordance with our matter, the potential damage to the State when payment is ordered in favor of a private party out of public funds based on an can not be reviewed and unfair decision.

Key words: Jurisdiction, arbitration, legal motivation. 


\section{INTRODUCCIÓN}

\section{Una aproximación sobre la institución arbitral}

Un experto como el profesor García Toma, señala que nuestro texto constitucional plantea asistemáticamente tres excepciones a la noción de jurisdicción (i) La jurisdicción arbitral, (ii) La jurisdicción militar, y la (iii) La jurisdicción de las comunidades campesinas y nativas. Señala el referido autor que la jurisdicción arbitral "es aquella que emana de la facultad de resolución extrajudicial de un litigio, pleito, controversia, duda o diferencia, que las partes otorgan al árbitro y que finaliza con una disposición llamada Laudo" agrega además el ex Presidente del Tribunal Constitucional que "el fundamento de la institución del arbitraje -cuya regulación legal se encuentra en el Decreto Legislativo $N^{\circ} 1071$ - radica en la necesidad de poner término en forma expeditiva y rápida a un litigio, así como en respaldar la confianza que las partes depositan en los árbitros"1.

Complementando lo expuesto, el profesor Bernales ${ }^{2}$, al analizar el artículo $139^{\circ}$ inciso 1 manifiesta que la función jurisdiccional ya se encuentra jerárquicamente y orgánica establecida; por consiguiente, no puede existir jurisdicción independiente, salvo las específicamente exceptuadas por la propia Constitución, (militar y la arbitral). Consecuentemente tanto la justicia militar, como la arbitral, no son autónomas ni pueden actuar de manera competitiva con la justicia ordinaria; ya que actúan de acuerdo con sus leyes y en el ámbito que la Carta Magna les faculta.

En discrepancia con los autores citados, Lohmann ${ }^{3}$, señala que la nota jurisdiccional que se adjudica al arbitraje, es excesiva.

1. Víctor García Toma, Análisis Sistemático de la Constitución Peruana de 1993., (Lima: Fondo de Desarrollo Editorial 1998), p. 453 y ss.

2. Enrique Bernales Ballesteros, La Constitución de 1993, (Lima: ICS Editores 1996), p. 554 y ss.

3. Juan Lohmann, El Arbitraje Vol. V (Lima: PUCP, Fondo Editorial 1993), p. 47 y ss. 
Pero arribemos a una cuestión de fondo; ya en 1981 Aramburu Menchaca ${ }^{4}$, en una nota publicada en un conocido diario local, opinó al discutirse el artículo $233^{\circ}$ de la Carta de 1979, se produjo un gran debate sobre considerar al arbitraje como jurisdicción independiente del Poder Judicial.

Aramburú, en la obra citada, indicó -con acierto- que la Constitución se refiere a la "Jurisdicción Arbitral”, empero procesalistas sustentaron que el arbitraje sólo era un juicio de naturaleza especial, o un procedimiento, como otros que considera la norma adjetiva. Triunfó el primer planteamiento (jurisdicción arbitral) y si bien existen otros planteamientos; impera lo que la Constitución dispone y ésta norma prima sobre las demás normas.

Es prudente apuntar que, con independencia de la posición doctrinal que adoptemos en relación a la naturaleza jurídica del arbitraje, para la académica Mallandrich " “...el arbitraje se origina en un acuerdo de voluntades..." Dicha postura -que por cierto compartimos- es la correcta; sin perjuicio que se pueda decir que, en el caso de arbitraje estatal, dicha postura no es clara.

\section{ANALICEMOS ESTA INSTITUCIÓN DESDE DOS ASPECTOS}

a) El Positivo. -

Para lo cual, en la gráfica siguiente señalaremos cual fue el tratamiento en el actual texto constitucional, como en su antecedente inmediato:

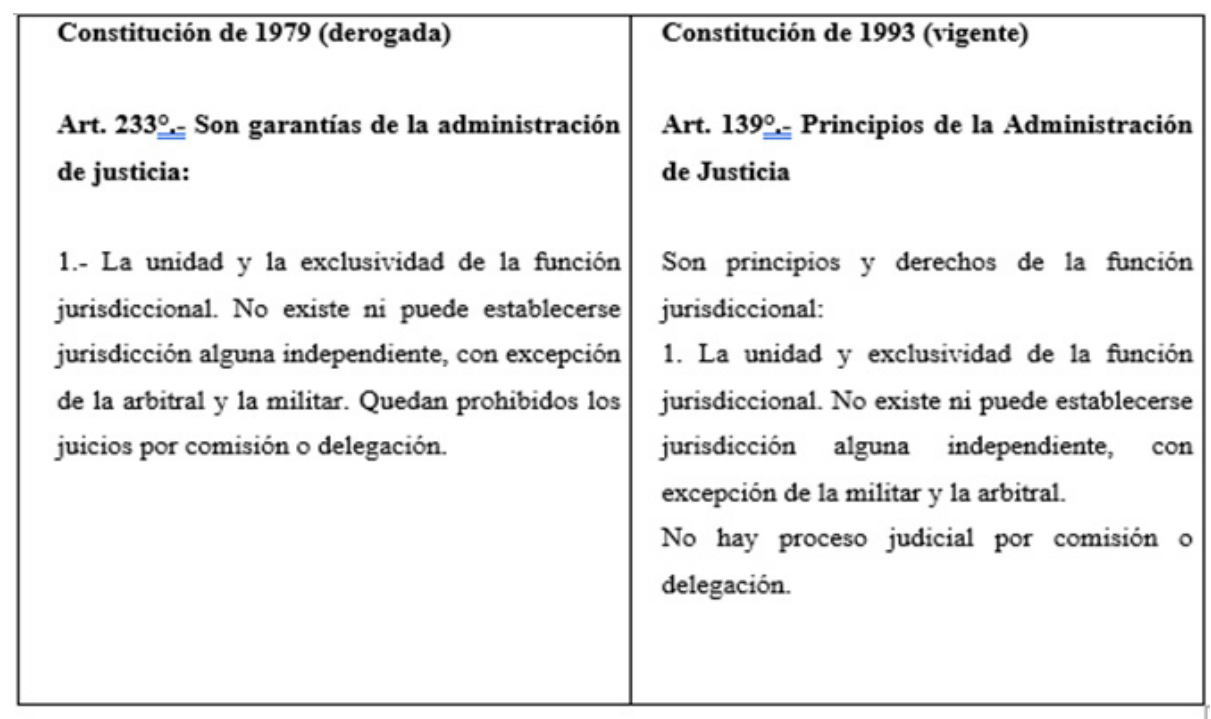

Elaboración propia

4. Andrés Aramburu, Notas al Margen de la Constitución. (Lima: Talleres Gráficos, 1990), p. 178.

5. Nuria Mallandrich, Medidas cautelares y arbitraje Atelier (Barcelona: 2010), p. 56 y ss. 
Como se ve, en ambos textos constitucionales (el derogado y el vigente) se prevé por excepción a la jurisdicción arbitral, es decir la misma norma fundamental señala que por excepción el arbitraje es jurisdicción. (Ver art. $139^{\circ}$ de la Constitución); es por ello que Bernales señala su existencia tanto de la jurisdicción militar como la arbitral.

b) Jurisprudencial

Si bien existen puntos de sana discordia intelectual, a nuestro modo de ver los postulados de orden doctrinario quedan fuera de toda discusión jurídica, amén de lo dispuesto en el texto expreso de la norma constitucional.

El Tribunal Constitucional, en la ilustrativa sentencia recaída en el expediente 06167-2005-PHC/ $\mathrm{T}^{6}$, de fecha 28 de febrero de 2006, en sesión de Pleno Jurisdiccional, emitió el pronunciamiento de fondo sobre el tema en cuestión mencionando el marco constitucional de la jurisdicción arbitral, indicando lo siguiente:

1. Justificación de la institución arbitral.

2. Naturaleza y características de la jurisdicción arbitral.

3. Criterios para el control constitucional de las resoluciones arbitrales.

4. Relaciones con la función jurisdiccional (artículo 139º, inciso 1 de la Constitución): Supuesto constitucional de excepción y la apreciación de razonabilidad.

Dice el supremo intérprete de la Constitución en la sentencia aludida que a finales del siglo XX la regulación del arbitraje obra en la mayor parte de las legislaciones del mundo y, se concibe a esta institución como el proceso ideal, en donde los particulares son protagonistas de la dirección y administración de la justicia. Así, el arbitraje se presenta como un mecanismo orientado a la consecución de la verdad legal, pretendiendo despojarse de los trámites, muchas veces engorrosos y formalistas, de la justicia tradicional. Entonces, históricamente en sus orígenes, el arbitraje se explicó en su carácter de proceso efectivo y expedito.

En el derecho comparado su desarrollo fue enorme, ya que es la vía más utilizada para la resolución de conflictos empresariales e incluso entre empresas y el Estado, (La normatividad de contratación estatal la prevé como mecanismo de solución de controversias en fase de ejecución contractual) lo que le otorga una importancia capital; conforme se indicará en las líneas precedentes la jurisdicción arbitral,

6. Como ya ha señalado el TC "la naturaleza de jurisdicción independiente del arbitraje, no significa que establezca el ejercicio de sus atribuciones con inobservancia de los principios constitucionales que informan la actividad de todo órgano que administra justicia, tales como el de independencia e imparcialidad de la función jurisdiccional, así como los principios y derechos de la función jurisdiccional. En particular, en tanto jurisdicción, no se encuentra exceptuada de observar directamente todas aquellas garantías que componen el derecho al debido proceso (STC N ${ }^{\circ}$ 00142-2011$\mathrm{AA} / \mathrm{TC})$ 
no vulneran el principio de igualdad ante la ley, previsto en el inciso 2 del artículo $2^{\circ}$ de la Constitución; siempre que dicha jurisdicción asegure al justiciable todas las garantías vinculadas al debido proceso y a la tutela judicial efectiva.

Llegados a este punto, cabe preguntarse ¿Es legítimo el establecimiento de esta jurisdicción de carácter temporal o privado?; nuestro Tribunal Constitucional señaló que el ejercicio de la jurisdicción implica cuatro requisitos, a saber:

- Conflicto entre las partes.

- Interés social en la composición del conflicto.

- Intervención del Estado mediante el órgano judicial, como tercero imparcial.

- Aplicación de la ley o integración del derecho.

Estos cuatro requisitos se dan en materia arbitral, pero vale indicar un agregado los jueces (y por extensión, también los árbitros) quedan vinculados a los preceptos y principios constitucionales conforme a la interpretación de los mismos que resulte de las resoluciones del Tribunal Constitucional, (aspecto que en la práctica no se da).

En este rubro, resulta importante indicar que, los principios ${ }^{7}$, según Dworkin ${ }^{8}$, son buen cuenta una exigencia de la justicia (valor supremo del Derecho), de esta manera, cumplen una función informadora, en tanto son la fuente material del Derecho, también, una función interpretativa, ya que orientan la creación del derecho positivo y orientan la interpretación (criterio interpretativo); y por último, tienen una función normativa o integradora, porque actúan como fuente supletoria de la ley.

Se podría decir que este instituto constituye en buena cuenta una necesidad, básicamente para la solución de conflictos patrimoniales de libre disposición y, sobre todo para la resolución para las controversias que se generen en la contratación internacional, en el cual el principio de la "kompetenz - kompetenz" faculta a los árbitros a decidir acerca de las materias de su competencia, sin injerencia de otra Institución. (Art. $3^{\circ}$ del Decreto Legislativo № 1071). El de motivación (Artículo 139, inciso 5), exigiendo la concordancia y la congruencia entre los considerandos y las partes dispositivas o resolutivas de las sentencias, lo que significa, por lo menos, que no se puede pedir que el cuerpo colegiado-sentenciador, diga una cosa en los considerandos, y la contraria en el fallo mismo.

Siendo Jurisdicción y fiel a las garantías del Estado Constitucional, resulta pertinente precisar la exigencia de motivación de las resoluciones arbitrales, la cual constituye una garantía constitucional consagrada en el artículo 139, inciso 5 de la Constitución Política, (Ejecutoria Suprema No 4223-2009

7. Los principios jurídicos son, criterios interpretativos: Para la aplicación de la norma; solucionar vacíos y como parámetro de actuación.

8. Ronald Dworkin, Filosofía del Derecho (México: Editorial Fondo de Cultura Económica, 1980), p. 86. 
Arequipa), con la cual se contará con una armonía lógica entre los fundamentos y el fallo, generando: Predictibilidad, Certeza y Seguridad Jurídica. Aspecto que en la práctica no se da, en razón que los laudos solo vinculan a las partes en conflicto, no frente a terceros. Dicho de otro modo, lo que resuelva el Laudo A, no causa precedente en el Laudo B, tal y como ocurre en Tribunales Administrativos, o en el propio Poder Judicial o Tribunal Constitucional.

\section{ARBITRAJE Y LAUDO}

Como sabemos, el arbitraje existió en Roma, pero fue después del año 476 D.C. cuando se produce su consolidación y será reconocido en distintos cuerpos legales como el Fuero Juzgo en 1241 y posteriormente en las Partidas elaboradas durante el reinado de Alfonso X. Para 1812, (Constitución de Cádiz), el arbitraje adquirirá rango constitucional.

En esa línea, el arbitraje nace del conflicto (y de las pretensiones de los contendores) y más aun de la inmediata necesidad de brindar una solución pacífica a las controversias entre los ciudadanos y sus empresas en un escenario distinto al judicial?

En nuestra realidad, en el Código de Enjuiciamientos en materia Civil del Perú de 1852, decía "Ejercen también jurisdicción las personas que los interesados nombran, conforme a este código, para que como árbitros conozcan en algún negocio particular”.

Posteriormente el Código de Procedimientos Civiles de 1912 señaló en su artículo 548 que: “Toda controversia sea o no materia de juicio, puede someterse a la decisión de uno o más árbitros. El número de éstos será siempre impar”.

\section{Un "Juez temporal" sin responsabilidades}

Si el árbitro tiene el mismo poder que un juez, también debe de tener las mismas responsabilidades. Podemos señalar válidamente la existencia de la naturaleza jurisdiccional del arbitraje, reconocido por la propia Constitución, la Doctrina y por el supremo interprete de la Constitución en diversas sentencias como la famosa STC Nº6167-2005-PHC/TC, entonces ¿Cuál es el impedimento para que decir que un Laudo no pueda ser susceptible de impugnación? O Será acaso que el "modelo de arbitraje peruano" está concebido para que pese a ser Jurisdicción, el Arbitro Único o Tribunal arbitral, no tengan las mismas obligaciones de cualquier Juez, o será acaso que el arbitraje como tal es una suerte de divinidad jurídica o jurisdicción incompleta ${ }^{10}$.

9. Anibal Quiroga, “Tesis para optar el grado de Magíster en Investigación Jurídica” (Pontificia Universidad Católica del Perú, 2017), p.58.

10. El 14 de setiembre del 2017, una universidad local realizó un conversatorio denominado ¿Un árbitro debe ser considerado funcionario público? En primer lugar, se presentó el representante del Fiscal de la Nación Pablo Sánchez, propulsor del proyecto de ley en cuestión. Daniel Pisfil presentó el contexto, precisiones y fundamentos para la propuesta de ley. A decir de Pisfil, el proyecto de ley 1774 responde a la política de integridad y lucha contra la corrupción del gobierno. Tendría un alcance solo para efectos penales y no administrativos, para responder a un vacío legislativo. No tiene como lógica la búsqueda de la sanción a un árbitro que lauda en contra del Estado sino que comete delitos. Refiriendo el derecho comparado, mencionó que en Brasil la ley 9307 considera a los árbitros como funcionarios públicos para efectos penales 
Si queremos, una verdadera alternativa al poder judicial, basado en especialidad y confianza, no vemos impedimento alguno a que -previa modificación legislativa- se pueda dar la posibilidad de una segunda instancia arbitral (la cual existía antes del 2008, con el art. 54 de la LGA, D. Ley No 25935 y el art. 60 de la Ley de Arbitraje, Ley 26572) y, que además los árbitros puedan sean comprendidos -como cualquier juzgador- en el delito de prevaricato, en los casos de laudos arbitrales manifiestamente contrarios a la razón y al Derecho, por todo ello existe pues una necesidad de evaluar la naturaleza inapelable de los Laudos Arbitrales en Materia de Contratación Pública, la cual se sustenta en Razón, en Justicia y sobre todo que en Democracia ${ }^{11}$ no existen intocables; máxime si la historia reciente nos demuestra que, grupos de poder compran jueces, atacan fiscales y colocan árbitros para resolver en uno u otro sentido, según las conveniencias del grupo dominante.

El principio de exclusividad de la función jurisdiccional, desarrollado por el Tribunal Constitucional (fundamento 15 de la STC Nº004-2006-Pl/TC), en su vertiente negativa, señala que los jueces (en nuestro caso lo árbitros) no pueden desempeñar otra función que no sea la jurisdiccional, salvo la docencia universitaria. Hasta aquí la redacción empleada no muestra mayor novedad, sin embargo, resulta contradictorio que en la práctica un mismo profesional sea árbitro, abogado litigante de forma individual o por medio de estudio de abogados en contra del Estado, consultor del Estado, funcionario público de confianza del Estado, secretario arbitral, (todo al mismo tiempo) es decir, ese mismo profesional (directa o a través de la firma de abogados en la cual es parte) tendrá información privilegiada que usará para en su momento para atacar al propio Estado peruano.

De lo expuesto no queda claro cuáles serían los sustentos -sí es que existen- del porqué, tanto el juez como árbitro tienen el poder de dirimir, pero en el segundo caso (el árbitro) tiene un abanico de prerrogativas, pero casi ninguna responsabilidad, como si lo tienen los magistrados del Poder Judicial, y nos referimos al caso puntual y concreto de como así un árbitro sustente en error sus laudos, sin embargo ese "error" deviene en irrevisable en la actual legislación nacional (véase la resolución de vista recaída en la 00321-2019-0-1817-SP-CO-02).

Muchos de los señores árbitros, atacarán este tipo de exclusividad, bajo el argumento que, el mismo deviene en inaplicable, por el hecho de no ser funcionarios públicos, olvidan nuestros amigos árbitros que, si bien no son funcionarios públicos, sus decisiones tienen relación directa con el destino de fondos públicos, por lo que un mejor tratamiento legislativo ayudará a clarificar la responsabilidad de los señores árbitros.

Por otra parte, se debe efectuar una modificación legislativa, a fin de contar con la habilitación jurídica y garantizar la prerrogativa del Procurador Publico de interponer el recurso de nulidad del laudo ante el Poder Judicial, sin interferencia y/o anuencia de autoridad alguna, ya que en mérito a lo

(Fuente: https://carc.pucp.edu.pe/nota-de-prensa/un-arbitro- debe-ser-considerado-funcionario-publico/). 11. La democracia presenta tres características: Igualdad, Tolerancia y Transparencia. 
ordenado en el artículo $47^{\circ}$ de la Constitución, concordante con el art. 6 inciso 2 de la Ley de Defensa Jurídica del Estado, D, Leg. 1326, es la potestad que posee el/la Procurador/a General del Estado, procuradores/as públicos y procuradores/as públicos adjuntos/as de organizar y ejercer sus funciones libres de influencias e injerencias, en concordancia con los demás principios rectores.

Este recurso, de naturaleza distinta al recurso de anulación, permitirá no solo ver el aspecto formal de laudo, sino el aspecto de fondo de la decisión o independientemente de la incomodidad de los señores árbitros retornas a la figura legal previa al año 2008 (D. Ley N² 25935 o la Ley No 26572, hoy derogadas), en el cual se permitía una segunda instancia arbitral, esto creemos adecuado, basándonos en el principio de flexibilidad que rige el arbitraje, así como en la autonomía de la voluntad de las partes.

\section{CONCLUSIONES}

a) No se debe valorar la experiencia en años de un profesional, la experiencia se mide por (i) décadas y por (ii) la actividad desempeñada. Ya que la decisión de un árbitro bisoño puede causar daños irreparables en el Estado, dada la actual naturaleza inapelable del laudo, la cual refutamos.

b) Aunque parezca un mito, a nivel de las normas del OSCE, no existiría sanción de orden administrativo para un árbitro que fundamente sus laudos en hechos contrarios a la verdad, algo impensado para un juez o un fiscal, conforme reza en artículo $418^{\circ}$ del Código Penal (prevaricato), para lo cual nos remitimos a los artículos $253^{\circ}$ y $254^{\circ}$ del Reglamento de la Ley de Contrataciones del Estado, (Código de Ética para el Arbitraje en Contrataciones del Estado, aprobado por Decreto Supremo 344-2018$\mathrm{EF})$.

c) No es adecuado que un mismo profesional, sea árbitro, abogado litigante de forma individual o por medio de estudio de abogados en contra del Estado, consultor del Estado, funcionario público de confianza del Estado, secretario arbitral, (todo al mismo tiempo) es decir, ese mismo profesional va a tener información privilegiada que usará para atacar al propio Estado peruano. Si un árbitro tiene casi las mismas atribuciones de un Juez, ¿Por qué no tener las mismas responsabilidades e incompatibilidades: prevaricato y exclusividad?

d) Se debe incluir en el modelo peruano la modificación del Código Penal, incluyendo a los árbitros en el delito de prevaricato, conforme a lo planteado en el Proyecto de Ley $N^{\circ}$ 4038/2018-CR. y desde el plano del derecho administrativo sancionador el Reglamento de la Ley de Contrataciones del Estado, (Código de Ética para el Arbitraje en Contrataciones del Estado), en los extremos ya señalados.

e) Debe ser prerrogativa del Procurador Publico interponer el recurso de nulidad de laudo ante el Poder Judicial, sin interferencia y/o anuencia de autoridad alguna, conforme a lo ordenado en el artículo $47^{\circ}$ de la Constitución, a fin de no solo ver el aspecto formal de laudo, sino el aspecto de fondo, por lo que rechazamos el numeral 45.23 de la actual de ley de contrataciones y, sostenemos esto entre otras razones por las siguientes: (i) Hoy se encuentra prohibido ver el aspecto de fondo de laudo, entonces un laudo malicioso, en cual deliberadamente se ordene pagar al Estado importes astronómicos 
no puede ser objeto de revisión ni cuestionamiento real. (ii) Ningún ser humano sobre la faz de la tierra es infalible, por lo que cabe la posibilidad de error e incluso dolo en la emisión de la decisión de fondo contenida en el laudo. (iii) Existe un marcado celo en los árbitros en que se revise sus laudos, y el tiempo nos da razón al contemplar uno a uno como los más conspicuos árbitros se encuentran vinculados en casos de corrupción en agravio del Estado.

f) Consideramos pues y, con el respeto a los señores árbitros honestos, que el arbitraje es un mecanismo casi perfecto de solución de controversias entre privados; en el cual las partes pueden pactar sobre la base de la autonomía privada lo que deseen en materia patrimonial. Pero en la actualidad existen serias dudas sobre la obtención de justica en materia de contratación públicos, por lo que previa modificación legislativa será potestad de las partes el optar por la jurisdicción común (Poder Judicial) debe conocer e $n$ primera y segunda instancia los conflictos derivados en el marco de la normativa de contrataciones del Estado, proponiendo a la Corte Superior de Justicia de Lima como ente competente a nivel nacional en primera instancia o por recurrir al arbitraje.

Reforzamos lo antes dicho con las siguientes líneas: Si bien el recurso de anulación tiene un contenido limitado y va dirigido a velar por el cumplimiento del procedimiento arbitral, (Resolución recaída en el expediente $\mathrm{N}^{\circ}$ 00514-2019-0-1817-SP-CO-01), existe pues un escenario sumamente contrario al valor supremo del derecho: "La Justicia" y es el contenido en la Resolución recaída en expediente 00321-2019-0-1817-SP-CO-02 de la Corte Superior de Justicia de Lima, la cual se dijo en el fundamento noveno:

“(...) las determinaciones del árbitro tanto en cuanto
a los hechos materia de la controversia como a la interpre-
tación que haga del Derecho aplicable y las conclusiones
jurídicas a las que llegue, por más erradas que éstas pudie-
ran estar, son inamovibles. La tarea de la corte se limita,
pues, a revisar la forma más no el fondo del asunto (...)”
(El subrayado es agregado)

No compartimos dicha argumentación, por el contrario, desde esta tribuna, creemos que dicha afirmación trasgrede no solo los principios jurídicos, sino la abundante jurisprudencia del Tribunal Constitucional, como lo es la STC N 1254-2004-PA/TC, en la cual se sostuvo que:

"la alegación de poseer derechos adquiridos presupone que estos hayan sido
obtenidos conforme a ley, toda vez que el error no genera derechos; por
consiguiente, cualquier otra opinión vertida con anterioridad en que se haya
estimado la prevalencia de la cosa decidida, sobre el derecho legalmente
adquirido, queda sustituida por los fundamentos precedentes", reiterada en la STC N $03059-2011-P A / T C$; 
Más aún, cuando en la jurisdicción arbitral lo que se busca es una decisión lo más justa posible, aquí cobra vigencia el planteamiento magistral de la académica Eugenia Ariano, respecto al caso del perdedor injusto; con un agregado, si conforme a nuestro modelo, desde el ańo 2008 no existe apelación, cuando menos es exigible al árbitro que motive según Derecho y sobre hechos ciertos, acreditados por las partes ${ }^{12}$.

Entonces, sobre la base de lo antes expuesto y dado el carácter inapelable del laudo, la exigencia de motivar el laudo tanto en los hechos, como en el derecho aplicable debe ser rigurosa; ya que, en el Perú, el accionar del árbitro puede ser equivocado, pero ese "error" dańa al Estado en materia patrimonial y esto en la actualidad es irreparable.

Dicho, en otros términos, se puede cometer cualquier aberración jurídica en el laudo, y no existirá razón humana capaz de revertir dicha situación. ¿Qué sucedería si se discute cualquier controversia de orden patrimonial "penalidades"; "resolución de contrato", "obligación de dar o hacer"?, y no se motiva, o se resuelve en error, o motivando sobre la base de hechos falsos o no se menciona siquiera las pruebas aportadas por la Procuraduría Pública (en el caso de Arbitraje con el Estado), el daño estaría consumado y su cumplimiento sería obligatorio desde su notificación (art. 59 de la actual Ley de Arbitraje), por lo que este tipo de decisiones de fondo que vulneran el principio de razón suficiente son irremediablemente perjudiciales en contra de los intereses del Estado. En estos casos merece una amplia reflexión del carácter inapelable del laudo ya que el mismo no se sustenta en la voluntad de las partes; sino muy por el contrario en la verticalidad de la ley.

\section{REFERENCIAS}

- Ariano, Eugenia .- Deber de Motivación Escrita de las Resoluciones Judiciales. Lima: Gaceta Jurídica. 2015.

- $\quad$ Aramburu, Andrés. Notas al Margen de la Constitución. Lima: Talleres Gráficos 1990.

- Bernales Ballesteros, Enrique. La Constitución de 1993. Lima: ICS Editores 1996.

- Dworkin, Ronald. Filosofía del Derecho. México: Editorial Fondo de Cultura Económica1980.

- $\quad$ Ejecutoria de la Corte Suprema de Justicia de la República del Perú - N4223-2009 Arequipa.

- García Toma, Víctor. Análisis Sistemático de la Constitución Peruana de 1993. Lima: Fondo de Desarrollo Editorial 1998.

12. Eugenia Ariano, Deber de Motivación Escrita de las Resoluciones Judiciales (Lima: Gaceta Jurídica, 2015), p. 653. 
- $\quad$ Lohmann, Juan. El Arbitraje. Vol. V. Lima: Pontificia Universidad Católica Fondo Editorial 1993.

- Mallandrich, Núria. Medidas cautelares y arbitraje. Barcelona: Atelier. 2010.

- Quiroga, Aníbal.- “Tesis para optar el grado de Magíster en Investigación Jurídica” . Pontificia Universidad Católica del Perú, 2017.

Sentencias del Tribunal Constitucional de la República del Perú:

- $\quad$ STC No 06167-2005-PHC/TC

- $\quad$ STC No 00142-2011-AA/TC

- $\quad$ STC N ${ }^{\circ} 1254-2004-\mathrm{PA} / \mathrm{TC}$

- $\quad$ STC N ${ }^{\circ} 0004-2006-\mathrm{Pl} / \mathrm{TC}$

RECIBIDO: $10 / 10 / 2021$

APROBADO: $25 / 11 / 2021$ 


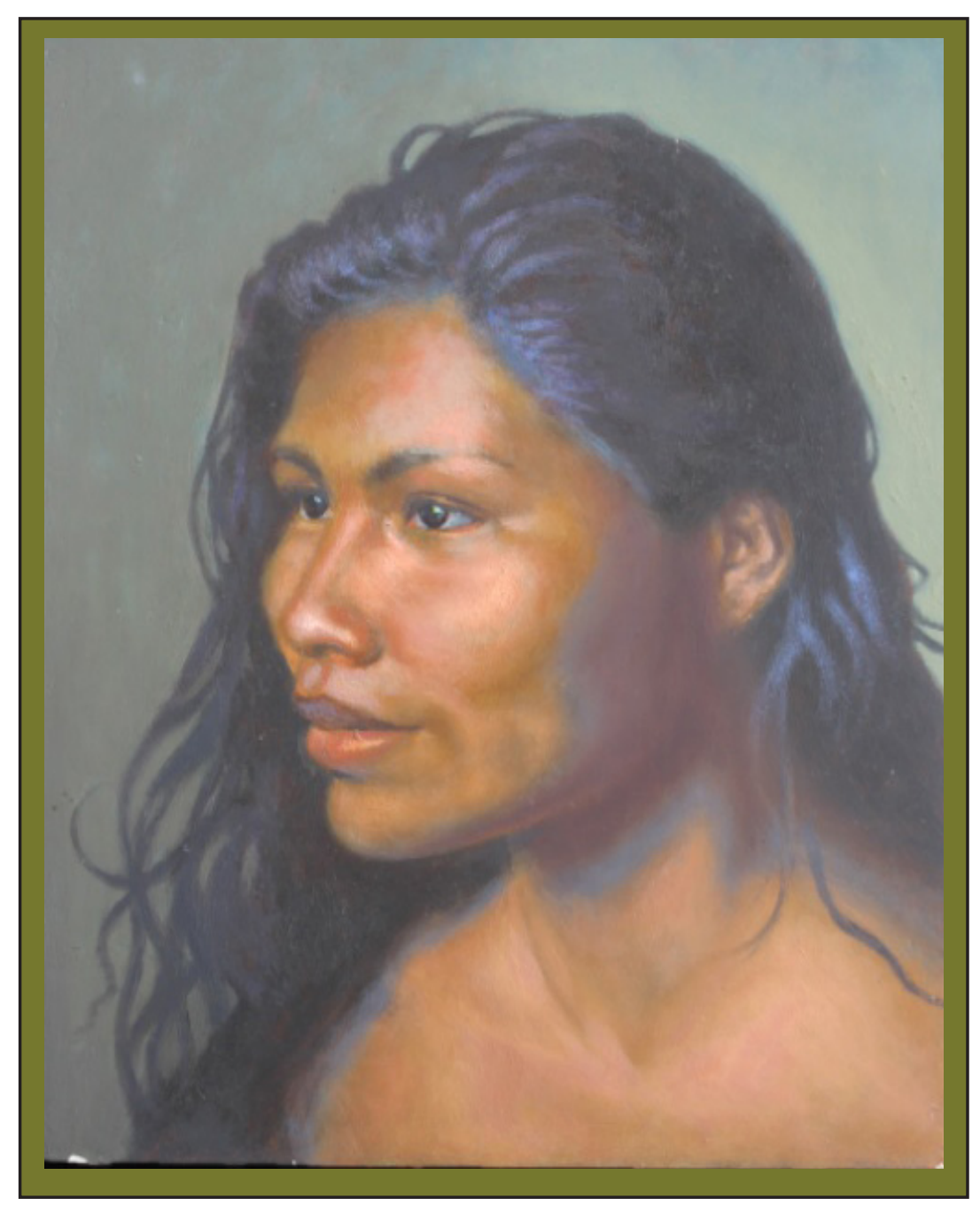

Awajuna. Óleo sobre madera 25 X $20 \mathrm{~cm}$.

David Hewson (EEUU, 1 966).

www.davidhewsonart.com 